\title{
Comportamento Estratégico e Turismo na Fronteira da Paz: estudo no setor de hospedagem
}

\author{
Strategic Behavior and Tourism in Fronteira da Paz: study in the lodging sector

\section{Comportamiento estratégico y Turismo en la Fronteira da Paz: estudio en el sector de} \\ hospedaje
}

Paulo Cassanego Júnior ${ }^{1}$

Nathalia De Simoni ${ }^{2}$

Jamur Marchi $^{3}$

\begin{abstract}
Resumo
Buscou-se identificar o comportamento estratégico das organizações da área de turismo da conurbação Fronteira da Paz. Para chegar à estes objetivos, foi realizada uma pesquisa qualitativa, descritiva e exploratória. Como método de coleta de dados utilizou-se entrevistas com perguntas abertas aplicadas aos administradores das organizações, com variáveis contruídas de estudos de Grangsjo (2003), Wang \& Krakover (2007) e Marchi (2006). A partir destas, quanto ao comportamento das empresas concluiu-se que as empresas não atingem graus significativos de confiança dentro do mesmo setor, resultando em relações curtas e esporádicas, impulsionadas em partes por vínculos de amizade, e que só ocorrem quando não é mais possível obter vantagens, em função da disponibilidade de recursos ser limitada, como ocorre quando não há mais capacidade de acomodação nos seus hotéis.
\end{abstract}

Palavras Chave: Turismo, Competição, Coopetição, Fronteira da Paz

\begin{abstract}
We tried to identify the strategic behavior of organizations in the tourism area of the conurbation Fronteira da Paz. To reach these goals, we conducted a qualitative, descriptive and exploratory research. As a method of data collection we used interviews with open questions applied to managers of organizations with constructed variables of Grangsjo (2003), Wang \& Krakover (2007) and Marchi (2006) studies. From these, about the behavior of firms, we found that companies do not reach significant levels of confidence within the same sector, resulting in short and sporadic relationships, driven in part by ties of friendship, and that only occur when there is

\footnotetext{
1 Doutorando em Administração pela Universidade de São Paulo (USP). Mestre em Administração pela Universidade Federal de Santa Maria (UFSM). Graduado em em Administração pelo Centro Universitário Franciscano. Professor Assistente da Universidade Federal do Pampa (UniPampa). Brasil. paulo.cass@gmail.com

${ }^{2}$ Graduada em Administração na Universidade Federal do Pampa. Brasil. nathisrrs @ hotmail.com

${ }^{3}$ Doutorando em Administração pela Universidade Federal de Santa Catarina (UFSC). Mestre e Graduado em Administração pela Universidade Federal de Santa Maria (UFSM). Professor Assistente da UniPampa.Brasil. Jamur.Marchi@unipampa.edu.br
} 
no longer possible advantage, depending on the availability of resources is limited, as occurs when there is more accommodating in its hotels.

Keywords: Tourism, Competition, Coopetition

\section{Resumen}

Tratamos de identificar el comportamiento estratégico de las organizaciones en la zona turística de la conurbación de Fronteira da Paz. Para alcanzar estos objetivos, se realizó una investigación cualitativa, descriptiva y exploratoria. Como método de recolección de datos se utilizaron entrevistas con preguntas abiertas aplicadas a los gerentes de las organizaciones con las variables construidas de Grangsjo (2003), Wang y Krakover (2007) y estudios de Marchi (2006). De éstos, sobre el comportamiento de las empresas, encontramos que las empresas no alcanzan niveles significativos de la confianza dentro del mismo sector, dando lugar a relaciones cortas y esporádicas, impulsados en parte por los lazos de amistad, y que sólo ocurren cuando hay ya no es posible ventaja, dependiendo de la disponibilidad de recursos es limitada, como ocurre cuando hay más flexibles en sus hoteles.

Palabras clave: Turismo, Competencia, Cooperación Competitiva

\section{Introdução}

As ações das empresas podem ser entendidas como comportamento estratégico, caracterizado por Ansoff (1983:16) como “o processo de interação com o ambiente acompanhado de um processo de promover a modificação das configurações e dos aspectos dinâmicos internos". Esta interação pode ser alçada a um nivel diferente daquele propagado pelos primeiros teóricos da área de gestão. Como afirmam Dyer \& Singh (1998:13) relational rents are possible when alliance partners combine, exchange, or invest in idiosyncratic assets, knowledge, and resources/capabilities, and/or they employ effective governance mechanisms that lower transaction costs or permit the realization of rents through the synergistic combination of assets, knowledge, or capabilities. Coadunando com este ponto de vista Powell, Koput \& Smith-Doerr (1996:118) afirmam que "firms thus turn to collaboration to acquire resources and skills they cannot produce internally, when the hazards of cooperation can be held to a tolerable level".

Ainda, Garcia \& Velasco (2002) afirmam que o comportamento exclusivamente competitivo gera retornos temporários e de curto prazo, tornando difícil para a empresa manter a competitividade estratégica no longo prazo. Neste sentido, a competição pode assumir novos formatos, fazendo com que as empresas se relacionem de uma forma inédita, colaborando 
com outras organizações para melhor competir $\mathrm{e}$ atingir melhores resultados (TEIXEIRA:2003; MATTOS; BELTRAND \& BERTÉ:2002 ).

Um setor onde podemos observar esta realidade é o setor turístico (LEITE \& TUROLLA, 2007:17-18). Nos últimos anos este vem se destacando como uma das atividades com maior potencial de crscimento. A partir da década de 80, a aceleração do processo de internacionalização e de abertura das economias nacionais provocou uma expansão significativa da atividade de turismo, fazendo deste o segundo setor mais globalizado da economia, perdendo apenas para o setor financeiro (SILVEIRA:2002; OMT:2009).

Sendo o setor turístico importante para o desenvolvimento local, levando-se em conta que esta atividade apresenta um ambiente propício para o desenvolvimento de parcerias, buscou-se analisar o comportamento estratégico e a forma das relações entre organizações na Fronteira da Paz, que envolve a cidade brasileira de Sant'Ana do Livramento e a uruguaia, Rivera. Este local tem a característica de ser uma conurbação binacional, dividindo um espaço comum, ininterrupto por qualquer obstáculo geográfico, ocasionando forte intercâmbio cultural, social e econômico. A partir disso, chegou-se à seguinte problemática: "Qual o comportamento estratégico das organizações do setor turístico na conurbação Fronteira da Paz?"

\section{Comportamento Estratégico}

Em uma contextualização sobre o aumento da concorrência e o crescimento econômico, Vázquez-Barquero (2002:18) expõe que o processo de globalização gera transformações econômicas, organizacionais, tecnológicas, políticas e institucionais, e propõe ser conveniente a adoção de uma visão econômica e social que permita considerar as respostas dos atores econômicos, identificando os mecanismos de desenvolvimento econômico. Neste ambiente de mudanças surgem diferentes teorias para explicar o comportamento e desenvolver estratégias para alcançar os objetivos das organizações.

Cavalcanti et al. (2007:323, 324) possuem uma visão holística do termo, a estratégia tem seu papel valorizado quando há necessidade de pensar novos caminhos e distinguir novos níveis de abstração, devido a extrema velocidade das mudanças, a imprevisibilidade da tecnologia e suas aplicações e os novos competidores. A autora resgata a importância do pensamento estratégico como um sistema sinérgico, que envolva todas as partes da organização, e que 
uma teoria de incerteza e mudança constante, possa coexistir com a estratégia, logo, o pensamento estratégico possibilitaria a empresa a gerar respostas rápidas para as atividades diárias. Frente a isso, serão apresentadas, como base para a pesquisa, o contexto das teorias da competição, da cooperação e da coopetição.

\subsection{Competição}

A competição, segundo Hitt; Ireland \& Hoskisson (2002:189), "resulta de uma série de ações e respostas competitivas entre firmas que concorrem dentro de uma indústria em particular". Sobre a abordagem competitiva, Dagnino \& Padula (2002) dizem que interdependência das empresas, tanto horizontal como vertical, é baseada no interesse individual. $\mathrm{Na}$ interdependência horizontal, as empresas buscam estratégias de criação de valor para obter maiores retornos econômicos. No caso de interdependência vertical, através de estratégias de apropriação de valor.

As diferenças de capacidades, competências e recursos existentes entre as organizações, provocam rivalidade entre elas, e as estratégias competitivas são utilizadas, de acordo com o ambiente em que estão estas empresas, a fim de desenvolver habilidades numa velocidade maior e a custos menores para aumentar sua vantagem competitiva, visto que há liberdade nos fluxos de capitais. De acordo com a estrutura das "cinco forças" (Figura 1) elaborada por Porter (1979), as organizações desenvolverão estratégias coerentes com os fatores não controláveis dentro da indústria a que estão submetidas. As cinco forças são: (i) as ameaças de novos entrantes, (ii) rivalidade entre empresas do setor, (iii) ameaças de produtos substitutos, (iv) poder de negociação dos compradores e (v) poder de negociação dos fornecedores.

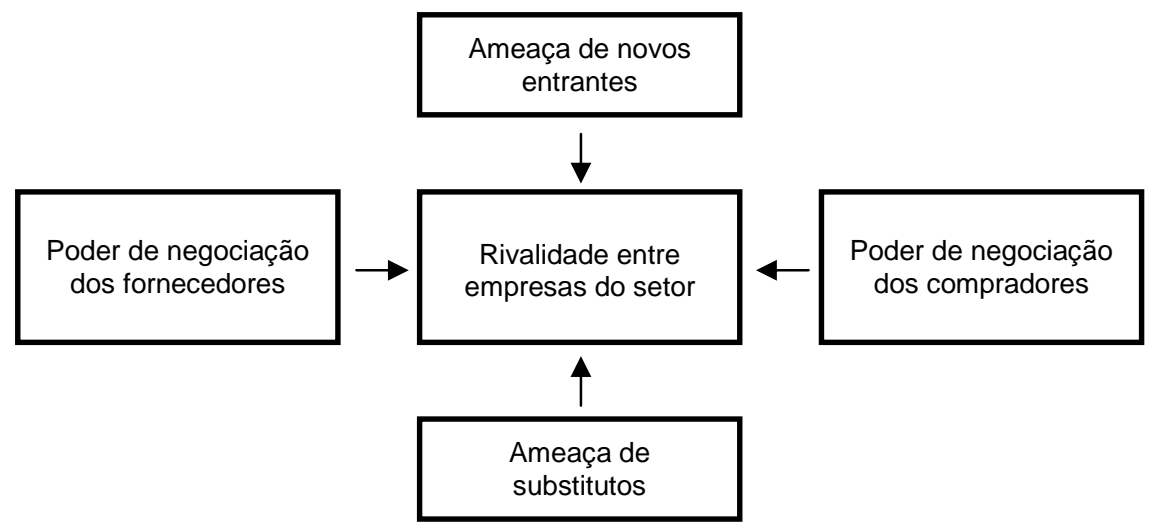

Figura 1 - Estrutura das cinco forças.

Fonte: PORTER, Michael. 1980:04. 
Estas forças influenciam a determinação dos preços, os custos, os investimentos necessários, e, principalmente, o posicionamento estratégico das empresas, visto que, a competição e a lucratividade são determinados pela estrutura setorial no médio e longo prazo. $\mathrm{O}$ entendimento desta estrutura serve como referencial para prever e influenciar a competição e a lucratividade a longo prazo, uma vez que são analisados não só os tradicionais concorrentes, mas também fornecedores, clientes, potenciais entrantes e produtos substitutos, ampliando assim a análise setorial.

Para competir neste mercado é necessario que as empresas criem vantagens competitivas e Porter em Vantagem Competitiva (1985) analisa a cadeia de valor das empresas como ferramenta para isto. Esta análise permite que as empresas entendam as partes de suas operações que criam valor e as que não criam, os custos, bases para diferenciação e os meios que poderiam ser utilizados para a implantação de uma estratégia.

A idéia principal da cadeia de valor, que mostra as fases de como um produto vai desde a matéria-prima até o consumidor final, é criar valor adicional sem incorrer em custos significativos e retornar esse valor criado, analisando os elos existentes entre estas atividades, a fim de alcançar vantagens competitivas que, frequentemente, são provenientes destes elos, da mesma forma que também são provenientes das proprias atividades individuais. Porter ainda afirma que existem os elos verticais, ou seja, entre a cadeia de uma empresa e as cadeias de valores dos fornecedores e dos canais, que afetam os custos e o desempenho das atividades de uma empresa. Quando as empresas não têm competências essenciais para a realização de suas atividades primárias ou de suporte, Porter (1989) sugere o compartilhamento de atividades semelhantes ou complementares entre si para a minimização de custos.

Contudo, Hoffmann (2000), ao relacionar o SCA - Sustainable Competitive Advantage - com outros conceitos, menciona que Porter's "value chain" approach focuses on activities within a single firm. A new model is needed which adapts his approach in order to understand the value-added processes comprised of dyadic and network interfirm activities which foster each firm's SCA. (HOFFMANN, 2000:2). Em oposição aos conceitos de competição surge a cooperação como um modelo que reúne empresas que, de forma inter-relacionada, tenham maiores possibilidades de competir no mercado de constantes mutações e gerar benefícios mútuos. 


\subsection{Cooperação}

A cooperação pode ser uma alternativa estratégica para empresas que não dispõem de competências essenciais ou estas são limitadas para a execução da atividade, a fim de garantir vantagem competitiva. Dagnino \& Padula (2002) afirmam que o mercado não é mais uma estrutura atomística com base na troca instantânea, mas torna-se um sistema de relações "interativas" e "contínuas", no qual os seus compromissos recíprocos das empresas são reforçados progressivamente, e realizam um processo de adaptação mútua e criação de valor conjunta. Afirmam Gulati, Nohria e Zaheer (2000:203) que the image of atomistic actors competing for profits against each other in an impersonal marketplace is increasingly inadequate in a world in which firms are embedded in networks of social, professional, and exchange relationships with other organizational actors.

Dyer \& Sing (1998) expõem que estudos recentes sugerem que os ganhos de produtividade na cadeia de valor são possíveis quando os parceiros comerciais estão dispostos a fazer investimentos especificamente relacionados e combinar os recursos de forma única (ASANUMA, 1989; DYER, 1996a, apud DYER \& SING, 1998). Eles ainda afirmam que isso indica que as empresas que combinam recursos de forma única, podem perceber uma vantagem sobre as empresas concorrentes que não conseguem ou não querem fazê-la.

Nas relações de cooperação devem ser destacados dois fatores importantes para facilitar as relações entre os diversos atores, segundo Marchi (2006), “estabelecer relações contínuas e não esporádicas entre os sócios e promover condições para que os sócios conheçam suas reputações". A Figura 3 é adaptada por Marchi (2006) a partir de Agostinho (2003), onde estão descritos os resultados da relação entre a "freqüência das relações" e a "reputação das organizações". Ao interpretar a figura, conclui-se que quando a freqüência das relações e a reputação são altas, tem-se um ambiente de alta cooperação, onde as relações entre os sócios são estáveis e a exploração das vantagens competitivas é alta. No quadrante contrário, onde a frequencia das relações e a reputação são baixas, o ambiente é de baixa cooperação, com relações medíocres e insustentáveis entre os sócios e as vantagens competitivas são impossíveis de serem exploradas. 


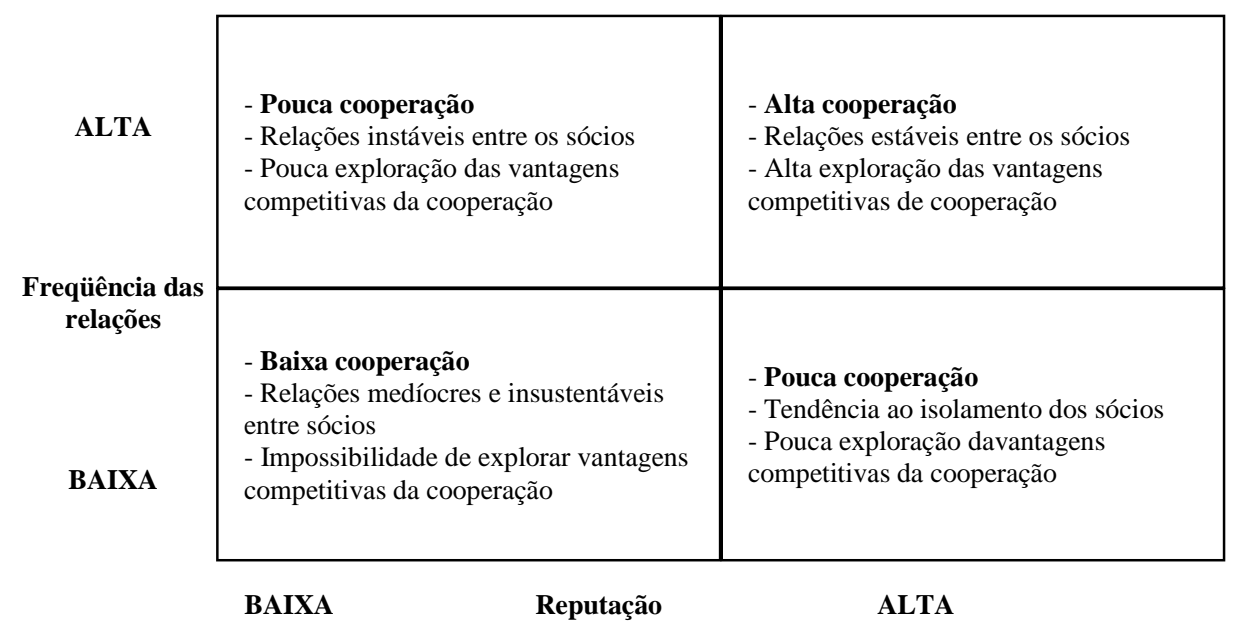

Figura 3 - Influência da freqüência das relações e reputação na cooperação.

Fonte: Elaborado por MARCHI, J. 2006, p. 55, a partir de AGOSTINHO, M. E., 2003, p. 69.

Por outro lado, Arrighetti et al. (2001, apud MARCHI, 2006) os custos de cooperar são sumarizados em três, o custo do oportunismo de um ator, o custo de coordenação e o custo de adaptação. O oportunismo é quando a contribuição de uma das partes é menor e espera apenas tirar vantagens das outras, o que tende a aumentar em grupos maiores. Na coordenação os riscos são menores que os de oportunismo, pois tendem a ser superados pelas vantagens de cooperar, e também tende a ser onerosa em maiores grupos. Custos de adaptação são ocasionados pelas mudanças necessárias dos planos individuais para encontrar a harmonia ideal nas relações. Frente a isso, Marchi (2006, p. 29) nota que a busca pela sobrevivência em um ambiente altamente competitivo faz com que as empresas, ao adotarem estratégias cooperativas, passem a observar os aspectos comportamentais de seus futuros parceiros, assim como ações de reciprocidade e compromisso em relações mais duradouras, e a necessidade de boa reputação e comportamento confiável.

De acordo com Wang \& Krakover (2007:130) a competição e a cooperação são duas lógicas opostas de comportamento das organizações. Em seus estudos sobre o comportamento nas organizações de turismo, afirmam, quanto à competição e a cooperação:

The competitive behavior is observed when individual tourism businesses try to maximize their own interests and do not participate in collective action. The different self-interests are often in conflict with each other, and as a result, businesses compete against each other to best fulfill their own self- 
interests. The cooperative behavior is based on a diametrically opposite rationale by which individual tourism businesses participate in collective actions to achieve common goals. (WANG \& KRAKOVER, 2007:130)

Já conforme Lado et al. (1997 apud LEÃO, 2004), as estratégias de cooperação formam-se a partir da competição, e estas, se realizadas em sua forma pura, não sustentam desempenhos superiores para as empresas, comparado àquele proporcionado pelo equilíbrio das estratégias de cooperação e competição. A estratégia de colaborar para competir tem sido definida por autores como "coopetição". Dagnino \& Padula (2002) sugerem a coopetição como uma nova categoria da interpretação da estratégia para as empresas se adaptarem ao ambiente dinâmico.

\subsection{Coopetição}

Segundo Dagnino \& Padula (2002), foram Brandenburger \& Nalebuff (1996) que inseriram o termo no campo da administração estratégica. Afirmam ainda que a cooperação e a competição se fundem para formar um novo tipo de interdependência estratégica entre as empresas, dando origem a um "sistema coopetitivo de criação de valor", visto que, de acordo com eles, em um mesmo ambiente estão presentes a competição e a cooperação. Nas palavras de Dagnino \& Padula (2002: 9):

The coopetitive perspective stems from the acknowledgment that, within interfirm interdependence, both processes of value creation and value sharing take place, giving rise to a partially convergent interest (and goal) structure where both competitive and cooperative issues are simultaneously present and strictly interconnected.

Segundo Marchi (2006:31), “a perspectiva da coopetição procura apontar para vantagens que as empresas podem auferir devido a um contexto cooperativo, mas que também permitem pressões competitivas". Oportunismo e confiança são variáveis comportamentais, geralmente coexistindo no mesmo contexto em diversos graus, que vão desde um nível de desconfiança até uma forte confiança, influenciadas pelo tempo e intensidade das relações.

1. Firms' interdependence is both a source of economic value creation and a place for economic value sharing;

2. Firms' interdependence is based on a variable-positive-sum game which may bring to mutual but not necessarily fair benefits to the partners because of several competitive pressures of different nature that may undermine their coopetitive structure; 
3. In a variable-sum game structure, firm interdependence is based on a partially convergent interfirm interest function (DAGNINO \& PADULA, 2002 p. 13).

Marchi (2006) identificou as variáveis existentes nesta inter-relação, como segue na Figura 5, que abrange as dinâmicas da competição, cooperação e coopetição.

\begin{tabular}{|c|c|c|c|}
\hline Dinâmica & Competição & Cooperação & Coopetição \\
\hline Visão da empresa & Independência & Interdependência & Independência e interdependência \\
\hline Estratégia & Competência essencial & $\begin{array}{l}\text { Interesses similares ou } \\
\text { convergentes }\end{array}$ & $\begin{array}{l}\text { Harmonia dos interesses } \\
\text { parcialmente convergentes }\end{array}$ \\
\hline Fonte de valor & Interna à empresa & $\begin{array}{c}\text { Nos processos } \\
\text { comuns/complementares entre } \\
\text { empresas } \\
\end{array}$ & $\begin{array}{c}\text { Nas diversas conexões entre as } \\
\text { empresas }\end{array}$ \\
\hline Visão da concorrência & Rivais & Parceiros & Coopetidores \\
\hline Relação entre empresas & Soma-zero & Soma-positiva & Soma positiva-variável \\
\hline Intensidade das relações & Curta & Duradoura & Flexível \\
\hline Comportamento das empresas & Oportunismo e desconfiança & Ajuda mútua e compromissos & $\begin{array}{l}\text { Ações de reciprocidade podendo } \\
\text { ou não alcançar confiança }\end{array}$ \\
\hline
\end{tabular}

Figura 3 - Dinâmica da competição, cooperação e coopetição.

Fonte: MARCHI, J. 2006:32

No mesmo contexto de coopetição, Yvone Grangsjo (2003) em seu estudo sobre destino turistico, afirma ser difícil separar cooperação e competição, uma vez que a maioria das empresas são interdependentes entre si. Em seu trabalho sobre teoria coopetitiva de negócios em uma de comercialização de um destino turístico dominado por microempresas empresas independentes. A autora demonstra que há dois diferentes conjuntos de valores no destino e que determinam a forma como as empresas estão envolvidas na rede.

Pelo turismo se tratar de um serviço e ser produzido em interação com o cliente, a autora afirma ser necessário que as empresas desenvolvam e comercializem seu próprio produto turístico, bem como o destino. A comercialização de um destino torna-se muitas vezes difícil por envolver muitas partes, cada qual com seus próprios objetivos, metas e motivações, que 
devem coexistir e colaborar com outras pessoas que desejam ou nao ter contato próximo, por estarem em uma área geografica limitada (GRANGSJO, 2003).

Grangsjo propõe a existência de duas perspectivas diferentes que coexistem em um mesmo ambiente, definidas em seu estudo como Gemeinschaft e Gesellschaft, que representam as normas e valores com que os empresários interpretam a realidade estabelecida, como isso influencia seu comportamento e o interesse do indivíduo na comercialização do destino. A primeira perspectiva, onde "a empresa serve aos interesses do destino", expressa que as empresas e os empresários operam o destino a partir de ligações emocionais. Predominam nesta perspectiva relações pessoais e emocionais. Na segunda, "o destino serve aos interesses da empresa", mostrando a racionalidade e atitude comercial desta perspectiva que expressa uma abordagem mais empreendedora.

Grandsjo reconhece sete dimensões que influenciam nas relações entre os atores do destino: normas e valores, sentimento comunitário, relacionamento, coopetição, rede, funcionamento do negócio e estrutura de rede.

Com base no estudo de Grangsjo (2003), Wang \& Krakover (2007) realizaram um estudo sobre as relações comerciais entre os intervenientes do setor de turismo na realização das atividades de marketing de destino colaborativo. Os autores identificaram que nas entidades ligadas ao turismo as diferentes relações de cooperação, competição e coopetição coexistem. $\mathrm{Na}$ perspectiva de cooperação, constataram vários graus de formalização, integração e complexidade estrutural nas relações entre as empresas no destino turístico: (i) afiliação, (ii) coordenação, (iii) colaboração e (iv) redes estratégicas. Estas relações vão de interligações informais por interesses semelhantes, no caso de afiliação, até o envolvimento de todas as organizações para alcançar objetivos do grupo, redes estratégicas.

Dos estudos de Grangsjo (2003), Wang \& Krakover (2007) e Marchi (2006), elaborou-se um quadro com as variáveis abordadas por estes autores e que serviram como base para esta pesquisa. 


\begin{tabular}{|c|c|c|c|}
\hline \multicolumn{4}{|c|}{ Perspectivas de análise } \\
\hline \multirow[t]{2}{*}{ Autor } & \multirow[t]{2}{*}{ Dimensão / Perspectiva / Dinâmica } & \multicolumn{2}{|c|}{ Comportamento da organização } \\
\hline & & Gemeinschaft & Gesellschaft \\
\hline \multirow{7}{*}{$\begin{array}{l}\text { Grangsjo } \\
(\mathbf{2 0 0 3})\end{array}$} & Normas e Valores & $\begin{array}{l}\text { Organização serve aos interesses do } \\
\text { destino }\end{array}$ & $\begin{array}{l}\text { O destino serve aos interesses da } \\
\text { companhia }\end{array}$ \\
\hline & Sentimento comunitário & Evoluído & Planejado \\
\hline & Relacionamentos & Irmãos e Irmãs & Estrangeiros \\
\hline & Coopetição & Cooperação ou competição & Competição \\
\hline & Rede & Rede social & Rede de negócios \\
\hline & Funcionamento do negócio & Fim em si mesmo & Lucro \\
\hline & Estrutura de rede & Independente & Controle \\
\hline \multirow{6}{*}{$\begin{array}{c}\text { Wang \& } \\
\text { Krakover } \\
\text { (2007) }\end{array}$} & & Cooperação & Competição \\
\hline & Normas e Valores & $\begin{array}{l}\text { Organização serve aos interesses do } \\
\text { destino }\end{array}$ & $\begin{array}{l}\text { O destino serve aos interesses da } \\
\text { companhia }\end{array}$ \\
\hline & Sentimento comunitario & Envolvido & Distanciado \\
\hline & Relacionamentos & Interdependente & Independente \\
\hline & Modelo de negócios & Cooperação & Competição \\
\hline & Pensamento estrategico & Macro & Micro \\
\hline \multirow{8}{*}{$\begin{array}{l}\text { Marchi } \\
(2006)\end{array}$} & & Cooperação & Competição \\
\hline & Visão da empresa & Interdependência & Independência \\
\hline & Estratégia & Interesses similares ou convergentes & Competência essencial \\
\hline & Fonte de valor & $\begin{array}{l}\text { Nos processos comuns/complementares } \\
\text { entre empresas }\end{array}$ & Interna à empresa \\
\hline & Visão da concorrência & Parceiros & Rivais \\
\hline & Relação entre empresas & Soma-positiva & Soma-zero \\
\hline & Intensidade das relações & Duradoura & Curta \\
\hline & Comportamento das empresas & Ajuda mútua e compromissos & Oportunismo e desconfiança \\
\hline
\end{tabular}

Quadro 1 - Perspectivas de análise

Fonte: elaborado pelos autores

A partir destas variáveis pode-se observar o comportamento das organizações dentro do ambiente em que atuam e em diversos setores, sob perspectivas diferentes. Viu-se na indústria do turismo, devido à interligação dos seus diversos setores e das organizações que a 
compõem, um ambiente oportuno para investigar o comportamento interorganizacional destas empresas. Frente à isso, abordaremos algumas questões relevantes do setor.

\section{Metodologia}

Para atingir o objetivo deste estudo, "conhecer o comportamento estratégico das organizações do setor turístico da conurbação Fronteira da Paz", serão utilizadas técnicas qualitativas (VENTURA, 2007; DESLAURIERS \& KÉRISIT, 2008:130). Logo, a pesquisa realizada pode ser considerada descritiva e exploratória (HAIR et al., 2005:83). A população pesquisada foi definida a partir dos cinco principais setores da indústria de viagens e turismo de Middleton \& Clark (2002:12), limitando-se ao setor de hospedagem.

No setor de hospedagem, a pesquisa foi aplicada nos principais atores do setor de turismo indicados pelo Secretário de Turismo da cidade de Santana do Livramento, em entrevista que foi gravada e transcrita. A amostra abrange hotéis, motéis e hotéis fazenda presentes na conurbação, que se situam no lado Brasileiro. Corresponde a nove organizações formalmente estabelecidos e apontados pelo secretário de turismo como os principais atores.

Os dados foram coletados e tratados no decorrer dos meses de outubro e novembro de 2009. Em um primeiro momento, estabeleceu-se contato por telefone para agendamento das entrevistas. E depois, para a realização das entrevistas propriamente ditas. Para coleta dedados foram utilizados dois instrumentos diferentes. Primeiramente, uma entrevista não estruturada com o Secretário de Turismo de Santana do Livramento para identificar os atores-chave do setor de acomodação da conurbação Fronteira da Paz.

A partir dos dados obtidos, foram realizadas entrevistas com os administradores dos hotéis. Com estes foi realizada uma entrevista semi-estruturada (COLLIS \& HUSSEY, 2005:160), por conceder a flexibilidade para incluir perguntas não-estruturadas, o que possibilita o "surgimento de informações inesperadas e esclarecedoras, melhorando as descobertas" (HAIR, 2005:163). O motivo dessa padronização foi o de obter dos entrevistados diversas respostas às mesmas perguntas, permitindo que elas fossem comparadas com o mesmo conjunto de perguntas e que as diferenças refletissem diversidades entre os respondentes e não diferenças nas perguntas (MARCONI \& LAKATOS, 2002:32). 
As entrevistas foram conduzidas da mesma forma, a fim de garantir que os respondentes entendessem os questionamentos da mesma maneira, visando uma equivalência de estímulo (COLLIS \& HUSSEY, 2005:161). Ao termino das entrevistas, as respostas foram transcritas e analisadas (RICHARDSON et al., 1999). As variáveis abordadas no questionário são provenientes dos trabalhos de Grangsjo (2003), Wang \& Krakover (2007) e Marchi (2006), como demonstrado no Quadro 1. A partir destas variáveis abordadas em estudos anteriores, fez-se uma adaptação. Partindo das variáveis do estudo de Grangsjo, percebeu-se a correlação com algumas variáveis de Wang \& Krakover.

A variável "Coopetição" de Grangsjo foi percebida como "Modelo de negócio", abordada por Wang \& Krakover. O mesmo ocorreu com a variável "Estratégia" de Marchi, percebida como "Pensamento estratégico" de Wang \& Krakover. A variável "Relacionamento" presente nos estudos de Grangsjo e Wang \& Krakover foi ampliada com as variáveis "Fonte de valor", "Visão da concorrência", "Tipo de Relação entre Empresas", "Intensidade das Relações" e "Comportamento Empresarial" percebidas no estudo de Marchi.

Logo, formou-se o seguinte arranjo: (1) Normas e Valores; (2) Sentimento Comunitário; (3) Rede; (4) Funcionamento do Negócio; (5) Estrutura de rede; (6) Modelo de negócio; (7) Pensamento estratégico; (8) Relacionamento; (9) Fonte de valor; (10) Visão da concorrência; (11) Tipo de relação entre empresas; (12) Intensidade das relações; (13) Comportamento empresarial emergente.

Tão logo obteve-se confiança no referencial construído, foi realizada a entrevista com o Secretário de Turismo, e as entrevistas com os gestores das organizações do setor de acomodação. Após foi realizada a preparação do material, ou seja, as transcrições das entrevistas. A partir destes resultados realizou-se a categorização dos mesmos (BARDIN, 2008), tendo como objetivo fornecer, por condensação, uma representação simplificada dos dados em bruto e depois, agrupados em variáveis de análise (temas). 


\section{Análise dos Dados}

\subsection{Normas e valores}

De acordo com Grangsjo (2003) as normas e valores das empresas influenciam na maneira que percebem a realidade, sob o prima de dois conjuntos de normas e valores que estão incorporados: Gemeinschaft e Gesellschaft. No primeiro, a empresa deve servir aos interesses do destino, expressa uma relação à área baseada em razões emocionais. No segundo, o destino serve aos interesses da empresa, expressa uma relação à área baseada em atitudes mais comerciais, atividades empresariais. Quando questionados sobre qual o tipo de relação que predomina nas relações com os demais atores da conurbação, cinco dos nove entrevistados respondeu predominarem as relações comerciais, como pode ser visto nas respostas dos entrevistados 7 e 4 :

Comerciais, levando em consideração preço, prazo, facilidades de pagamento. (ENTREVISTADO 7)

São relações mais comerciais, numa proporção de $70 \%$ comercial e $30 \%$ emocional. (ENTREVISTADO 4)

Estas relações se referem ao relacionamento com fornecedores. Porém, também são citados os relacionamentos com os demais hotéis, percebeu-se que, neste caso, são preservados valores como amizade, mas que não chegam a se traduzir em parcerias, em função de não se atingir níveis de confiança e reciprocidade com os outros atores.

Em Santana do Livramento, nesse período agora, não está havendo muito relacionamento, não sei o porquê. A hotelaria está funcionando muito bem, mas os hoteleiros não estão se unindo. [...] Então, o hotel se relaciona com os demais [atores da conurbação], mas é comercialmente. (ESTREVISTADO 1)

Com os fornecedores já aparecem mais relações de comprometimento, uma vez que se criam dependências por ambas as partes, mas ainda assim, baixos níveis de confiança.

Ah, isso depende, se há uma parceria do outro lado também, a gente pode levar até pelo lado emocional também. Tudo vai depender da negociação, do tempo de negociação que tu tem com tal empresa, com tal fornecedor e questão também de cumprir com os prazos de entrega, prazos de validade do produto. Às vezes não se paga pelo melhor preço, mas se paga pelo melhor 
produto, então isso aí é uma relação que depende, tudo isso vai depender. (ENTREVISTADO 8)

Contudo, a tendência a ter relações mais comerciais mostra a visão dos atores, quanto às suas normas e valores, que, devido a predominância deste tipo de relação, percebem o destino como um meio de servir aos interesses das empresas. Nota-se que há presença de vínculos de amizade, mas não prevalecem, o que confirma a existência dos dois conjuntos de normas e valores e o fato deles estarem incorporados um no outro. Os níveis de desconfiança com os empresários que possuem atividades iguais é considerado alto, tanto que não foram estabelecidas parcerias que poderiam ser consideradas proveitosas, visto que as relações comerciais podem garantir o desenvolvimento dos negócios e as emocionais a preservação de normas e valores. Estas, se percebidas e realizadas em conjunto podem servir como base para possíveis estratégias de comercialização do destino.

\subsection{Sentimento comunitário}

Grangsjo (2003), enfatiza a necessidade das atitudes comerciais e emocionais ao mesmo tempo na comunidade, uma vez que a atitude comercial é necessária para a sobrevivência a longo prazo do destino o que garante a geração de lucros que permitam novos investimentos; e os vínculos pessoais do empresário para garantir que os valores comuns da comunidade serão preservados e mantidos. A autora destaca dois conjuntos de sentimento comunitário: evoluído - quando há uma relação de dependência do ambiente - e planejado, quando independe a comunidade em que está situada. Quando questionados sobre qual o tipo de envolvimento que a empresa possui com a comunidade, na maior parte das respostas foi observado claramente a existência de uma dependência da fronteira como destino e fator impulsionador do negócio.

As duas cidades são importantíssimas, o transito que nós temos do turista, tanto uruguaio como brasileiro e de outros países do MERCOSUL que fazem parte, é o que realmente nos dá força para trabalhar e pra desenvolver, para ter um crescimento. (ENTREVISTADO 2)

Algumas empresas estão envolvidas também com causas sociais e dispostas a colaborar com a comunidade: 
Nós temos que ter um relacionamento com toda a comunidade, dar apoio a eventos, a qualquer coisa que o município precisar. Estamos sempre aí... Sempre dando apoio para ter um relacionamento com a comunidade. (ENTREVISTADO 1)

Em outras respostas foi observado que há dependência do destino, como o próprio entrevistado afirma, mas que não estão envolvidos com causas sociais.

Depende sim, certamente. Não temos como esquecer a fronteira aqui. Somos duas cidades em uma e trabalhamos pura e exclusivamente em uma grande porcentagem com o turismo brasileiro, sem duvida alguma. [...] Não tem nenhum foco que a empresa colabore diretamente, como já disse, salvo casos excepcionais como tem sido o tema das inundações. (ENTREVISTADO 3)

Dentre as 9 respostas obtidas, duas foram negativas, afirmando que não há uma relação de dependência com a comunidade/destino como um todo.

Constante busca das parcerias, porque entendo que a atividade turística é tremendamente democrática, ou seja, todos têm oportunidades e são importantes. [Quanto à dependencia do ambiente] $\mathrm{O}$ ambiente ajuda, mas não é fundamental, embora esta fronteira sempre seja um destino importante, principalmente no segmento do "Turismo de Compras", as articulações com os outros segmentos (Esportivo/Religioso/Cultural/Eventos/Rural/etc.) são também muito necessárias e infelizmente pouco ocorrem. $\mathrm{O}$ trade turístico, que envolve todos os agentes (públicos e privados) é totalmente desarticulado e amador. O Turismo de Compras, que é o nosso "grande gancho" impulsionador é realizado do outro lado (Uruguay) e, portanto, não são realizadas ações conjuntas de melhorias, principalmente da infraestrutura, perdendo-se grande parte deste "tão sonhado fluxo". As pessoas reclamam do mau atendimento, do trânsito e estacionamentos, da falta de opções de lazer e cultura, da falta de informações sobre os meios de hospedagem e gastronomia. Nunca foi feito uma pesquisa junto aos "turistas", para detectar, quantificar e estabelecer ações conjuntas (campanhas) corretivas e impulsionadoras. (ENTREVISTADO 8)

Nota-se que o sentimento de envolvimento com a comunidade/destino é importante para preservar os valores comuns da comunidade, porém é importante ter, simultaneamente à este envolvimento, atitudes racionais, comerciais, para garantir novos investimentos. Ter uma atitude de planejamento é importante para, como mencionou o Entrevistado 8, perceber que as articulações que movem o setor devem trabalhar de forma sinérgica, para que a fronteira seja vista como um conjunto, com um destino turístico completo, com opções de atrações 
diferenciadas e peculiares à região, infra-estrutura adequada, envolvimento dos setores público e privado, para oferecer uma experiência positiva ao turisma e o destino ter maior competitividade frente aos outros destinos.

\subsection{Funcionamento do negócio}

Nesta variável, é analisado como os valores da empresa interferem na sua conduta de funcionamento do negócio, tendo o fim em si mesma ou apenas no lucro. Se a empresa tem uma atitude comercial no que diz respeito ao destino, então ela pode entrar em conflito com outros valores representados pelo produto do destino (GRANGSJO, 2003). Quando questionados quanto ao funcionamento do negócio, os entrevistados enfatizaram a importância de se levar em consideração outras atividades para que a empresa continue atuando de forma sustentável, enfatizando a geração de lucros, mas não como fator exclusivo de sua existência. Neste sentido, os respondentes citam atividades que proporcionam a criação de valor e que não podem ser ignoradas, como parte da geração de lucros.

Tem fim nos dois. Ela [a empresa] valoriza tanto a imagem, quanto a lucratividade. Não adianta tu ter uma imagem boa e não ter lucratividade. Antigamente até se pensava nisso, fazer uma imagem grande pra depois fazer uma comercialização grande da sua imagem. Só que hoje em dia as duas empresas e os dois lados têm de estar casados. Um ligado ao outro. (ENTREVISTADO 8)

Em uma única situação não foi considerado o fim em si mesmo.

A empresa vive de resultados positivos, visando lucro, com certeza. (ENTREVISTADO 7)

Nas respostas observou-se que são levados em consideração, e entendido pelos entrevistados como fim em si mesmo, o comprometimento das empresas com atendimento ao cliente, qualidade de produtos e serviços à eles ofertados e investimento em melhorias para o negócio.

\subsection{Rede}

Quanto às redes em que as empresas estão inseridas, Grangsjo (2003) distingue que, de acordo com o comportamento das organizações, elas podem ser de duas maneiras: redes sociais, abertas; e redes de negócio, formalmente estabelecidas. Quando questionados sobre o 
tipo de rede predominante nas suas relações, cinco respondentes afirmaram que predominaram as relações comerciais. Porém, em um único caso foi mencionado, no decorrer da entrevista, constatou-se a existência formal de uma rede de negócios, nos demais não houve esta constatação. Em contrapartida, há respostas que confirmam a existência de uma rede aberta, social.

Com outros hotéis, aqui na cidade mesmo, temos conhecidos que têm hotéis, temos um relacionamento normal, de amizade, mas comercial não. (ENTREVISTADO 6)

Considerando o relacionamento com os outros hotéis, percebeu-se a existência de uma rede social, porém, caracterizada por atitudes de competição, visto que só há este contato na rede quando suas capacidades de hospedagem estão plenas.

Mais emocional, mais social. Porque eu faço contato com todos os hotéis. Porque tem hotéis que procuram nem se comunicar, viver a vida deles. Eu não, no momento que eu estou recebendo hóspedes e estou com o hotel cheio, eu faço contato com outros hotéis, e eu mesmo pego o meu carro e levo em outros hotéis. (ENTREVISTADO 4)

Um dos respondentes abordou o relacionamento com os clientes e formas de marketing, definindo como como uma rede aberta, pela predominância da divulgação informal, como o "boca a boca".

Dentro desta classificação eu diria que é a rede social, pois embora usemos uma série de recursos modernos de marketing (site/logomarca/realising/pautas para redações/etc.) na divulgação de nosso empreendimento, o predomínio absoluto continua sendo do antigo "boca à boca". As normas de qualidade para o Turismo atualmente são óbvias, pois agora está se exigindo a excelência. Surprender e encantar os clientes são as palavras-chaves para quem quer ter sucesso e se manter lá. O tipo de Turismo que praticamos (TR) é classificado pelos órgãos oficiais (SETUR/EMBRATUR) como uma Casa de Fazenda e não um Hotel. A proximidade, a intimidade e a descontração proporcionadas pelo tipo de atividade (Pousada Familiar com 04 aptos) conduzem naturalmente às pessoas ao relaxamento, a intimidade e às amizades. Portanto como costumamos dizer: "O Turismo Rural não é um meio de vida e sim um modo de vida". (ENTREVISTADO 9) 


\subsection{Estrutura de rede}

Powell (1990) afirma que todas as empresas estão envolvidas em uma rede, com diferentes formas de conexões e intensidade. Esta rede, conforme Grangsjo (2003), pode ter duas estruturas: as empresas com uma grande rede externa, ou seja, fora da comunidade, e as empresas com uma rede interna, na comunidade. Os empresários que fazem contato com a maioria dos seus clientes/comprador antes que eles cheguem ao destino tem uma rede consistindo principalmente de contatos externos, ou seja, com empresas fora da comunidade.

Os administradores dos hotéis, quanto à esta estrutura, responderam que, em função de seus negócios serem baseados no serviço de hospedagem, trabalham, essencialmente, com pessoas vindas de outras cidades e regiões, tanto turistas como representantes comerciais em transito pela região, apesar de alguns responderem ser apenas interna. Quanto ao marketing, as empresas realizam fora da comunidade, porém, de forma individual. O relacionamento de amizade com moradores locais e também com hóspedes, promove um tipo de propaganda informal, onde os mesmos indicam os hotéis.

O Turismo depende diretamente do turista (viajante) que vem de fora, portanto todo o marketing é externo. No entanto diversas ações no plano interno (local) são indiretas e muito necessárias para uma correta articulação com os outros empreendimentos dos diversos segmentos turísticos (particulares e oficiais). (ENTREVISTADO 9)

Quanto às compras, percebeu-se que eles têm preferência em realizá-las dentro da comunidade. Esta atitude pode ser influência de suas normas e valores, priorizando, quando possível, fomentar as atividades comerciais na comunidade.

[...] As compras maiores são realizadas em conjunto com os hotéis da rede a qual estamos vinculados, mas temos nossos fornecedores locais, e buscamos manter uma relação que gere benefícios para ambos. Buscamos estender um padrão de qualidade à eles também, pois precisamos de bons produtos para oferecer ao nosso hóspede, e é preciso que eles nos ofereçam estes produtos com qualidade também. (ENTREVISTADO 5) 
Porém, empresas que atuam em outros segmentos a estrutura de sua rede, quanto aos fornecedores é externa, em função de preços, disponibilidade de produtos, e, em algumas situação, em função da qualidade, como pode ser observado nas seguintes respostas.

\begin{abstract}
A maioria dos fornecedores é de fora. Nós temos a mão-de-obra interna, mas o material que consumimos, com exceção das distribuidoras que são locais, a maioria vem de fora, [...] vem de outros estados, outros municípios, dentro do nosso país. (ENTREVISTADO 2)
\end{abstract}

Percebe-se, então, que a estrutura de rede varia em relação às atividades, se analisarmos a partir da cadeia de valor. A estrutura de rede de clientes é externa, visto que são empresas do setor de acomodação e trabalham essencialmente com turistas nos finais de semana, e com representantes comerciais, durante a semana. Seguindo o mesmo princípio, o marketing é direcionado para fora da comunidade, mas com forte presença de indicações de outros hóspedes. Quanto às compras, pode-se notar a preocupação em desenvolver o comércio e a mão-de-obra local. A estrutura de rede com fornecedores externos foi detectada nas empresas que atuam em outros segmentos simultaneamente.

\title{
4.6 Modelo de negócio
}

Wang \& Krakover (2007), em um estudo realizado sobre marketing de destino, identificaram nas entidades ligadas ao turismo, que as diferentes relações de cooperação, competição e coopetição coexistem. Este fato pode também ser percebido na comunidade em estudo, a Fronteira da Paz. Não houve incidência de casos de empresas baseadas exclusivamente na cooperação. Wang \& Krakover (2007) estabeleceram quatro níveis de formalização entre empresas sob a perspectiva cooperativa, que vai de interligações informais (afiliação) até o envolvimento de todas as organizações para alcançar objetivos comuns (redes estratégicas). Em apenas um dos casos foi verificada a existência de um tipo de cooperação, ao nível de “coordenação" (Wang \& Krakover, 2007), em âmbito local, onde as organizações autônomas alinham atividades para um serviço em particular, orientados para a busca de objetivos compatíveis. Esta mesma organização pertence a uma rede de hotéis, mas cada um deles é de administração independente. Esta relação de coordenação pode ser verificada com a resposta do entrevistado 5 . 
O nosso hotel tem relação com uma rede de hotéis presente em outras cidades.[...] As compras são realizadas em conjuntos com os outros da rede. [...] Nós percebemos as outras empresas [dentro da comunidade] como potenciais parceiros, tanto que temos uma parceria com um free shop. O pessoal do free shop vêm até o hotel à noite para mostrar aos hóspedes perfumes e oferecem degustação de bebidas variadas. No outro dia, eles [os hóspedes] vão até o free shop para comprar. Para nós é ótimo, pois oferecemos um serviço diferenciado para os nossos hóspedes, que muitas vezes preferem ficar no hotel para descansar e no outro dia ir às compras, e para o free shop também, porque o pessoal vai direto lá. (ENTREVISTADO 5)

Em outros casos, a relação é de competição, visto que atuam com seus próprios recursos e capacitações, como afirmam na variável "fonte de valor", sendo esta "interna".

Nós zelamos muito pela empresa, de melhorar. Nós não pensamos em competição, pensamos em melhorar. [...] Dentro desse melhoramento a gente tá competindo. A gente mantém até, dentro do mercado, diárias acessíveis para que o turista venha nos procurar e indicar o nosso hotel. [...] Por enquanto não temos [nenhum tipo de cooperação], temos um projeto para trazer pessoas de outras cidades, um tipo de pacote. [Quanto à outros hotéis] cada um trabalha individual dentro da sua forma, cada um tem q ter uma criatividade própria. (ENTREVISTADO 1)

Percebe-se também que apesar das empresas terem um modelo de negócio de competição com os demais atores da comunidade, as relações de amizade, estabelecidas ao longo do tempo, estão presentes informalmente entre elas, uma vez que os hotéis, quando estão operando com sua capacidade total, entram em contato com os demais para atender as necessidades do turista. Ressalta-se que esta "cooperação" só ocorre no momento em que suas instalações já estão completas, caso contrario, poderia não ocorrer. Esta atitude caracteriza um modelo de competição.

Os dois simultaneamente. Por exemplo, se o hotel está lotado eu forneço o telefone de todos os outros da cidade, sem problema algum. E se a pessoa precisa de um telefone de outra empresa eu forneço, sem problema algum. (ENTREVISTADO 7)

Em um dos casos, o entrevistado expõe uma situação de coopetição claramente.

Os dois simultaneamente. Cooperação quando prestamos o serviço de informações sobre os nossos meios de hospedagem rurais 
(Pousadas/Fazendas) por e-mail e/ou telefone aos turistas que entram em contato. As cidades de Livramento e Rivera não possuem este serviço de Central de Reservas e Informações. Competição quando os turistas optam pela hospedagem na nossa pousada em relação à hotelaria local. A nossa hospedagem é completa, com refeições e atividades. (ENTREVISTADO 9)

Entre os entrevistados percebeu-se a coexistência dos diferentes modelos de negócio no mesmo ambiente, com predominância do modelo de competição. Porém, não ocorre em sua forma pura, uma vez que podem ser observadas, em algumas situações, atitudes de relacionamento informais interfirmas.

\subsection{Pensamento estratégico}

O pensamento estratégico é considerado por Wang \& Krakover (2007) com um dos fatores influentes na configuração das relações entre as empresas. Pode ser pensado sob duas perspectivas: micro e macro. Na perspectiva micro as empresas têm menor probabilidade de trabalhar com outras empresas de turismo. Seu foco é sobre como criar e manter vantagens competitivas por meio de esforços de seu próprio negócio. Na macro, tendem a trabalhar mais uns com os outros, concentrando-se no comum benefícios do destino.

Ao questionar os entrevistados sobre o pensamento estratégico da sua empresa houve a necessidade de definir as duas dimensões que pode ser pensado. Sete dos nove entrevistados afirmaram pensar estratégia na dimensão macro, como pode ser visto nas respostas, e apenas dois responderam ser micro.

É macro por que pensamos em fazer parceria com outras empresas de transporte, [...] inclusive dentro dessa parceria, seria, em vez de fazer excursões, trazer o pessoal com diárias incluídas, fazer um tipo de pacote com essas empresas [...] para atrair mais clientes. (ENTREVISTADO 1)

$\mathrm{Na}$ análise isolada destas respostas, os entrevistados afirmam pensar estratégia sob a perspectiva “macro". Porém, percebeu-se que suas atitudes são contrárias às suas afirmações, uma vez que as relações com os demais atores não atingem níveis consideráveis de comprometimento e confiança, não trabalhando uns com os outros em benefício do destino. Suas vantagens competitivas são criadas internamente, ou seja, por esforços do próprio negócio, claramente exposto pelo entrevistado 9. 
Esta classificação poder tornar-se muito sutil, dependendo da interpretação. Quando divulgamos o nosso empreendimento junto com os outros, fora desta região (RS/Brasil/Exterior) estamos pensando "macro". Quando estamos melhorando as estruturas e a qualidade do atendimento, estamos pensando "micro". (ENTREVISTADO 9)

\subsection{Fonte de valor}

Marchi (2006) analisa a fonte de valor das empresas sob três dinâmicas: competição, cooperação e coopetição. Na dinâmica de competição a fonte de valor, segundo o autor, é interna à empresa, isto é, a criação de valor se da no nível da empresa (DAGNINO \& PADULA, 2002). Na de cooperação, Marchi (2006) define que as empresas buscam valor nos processos comuns/complementares entre empresas, ou seja, "a criação de valor pode ser um processo comum que acontece entre dois ou mais atores e a meta é compartilhar benefícios mútuos" (MARCHI, 2006:29). Na dimensão de coopetição, o mesmo autor considera que a fonte de valor tem origem nas diversas conexões entre as empresas, ou seja, a fonte de criação de valor pode ser a interdependência das empresas. Quando questionados sobre qual a fonte de valor de suas empresas, os administradores responderam ser interna.

É interna. [...] Meu hotel está sendo reconhecido [...] em função do ambiente familiar que tem aquela participação de pessoas que pela primeira vez vem e se sentem em casa, não tem nenhuma discriminação nem muitos protocolos, então o pessoal tem condições de se sentir quase em casa. (ENTREVISTADO 4)

Apesar de algumas respostas obtidas afirmarem o contrário, percebeu-se, com base na cadeia de valor e levando em consideração as respostas obtidas para outras variáveis de análise, que na atividade de marketing, mesmo que de forma informal, ocorrem situações de relacionamento entre as empresas e os moradores locais e entre os clientes, em função das relações de amizade estabelecidas. As demais atividades são internas.

Em apenas um dos casos, constatou-se que a fonte de valor ocorre também nas relações interfirmas, nas conexões com outras empresas, como no caso do entrevistado 5. Esta empresa compartilha atividades como aquisição, marketing e vendas e serviços com as demais empresas da rede a qual está vinculada.

Nós temos algumas atividades compartilhadas com outros hotéis [da rede a qual estão vinculados], como por exemplo as compras maiores, são feitas 
pela rede. Temos também parceria com free shops, que trazem um serviço diferenciado para os nossos hóspedes. (ENTREVISTADO 5)

Ao relacionarmos a variável "pensamento estratégico" com a "fonte de valor", confirma-se, entre os entrevistados, a contradição no seu comportamento. Este pensamento "macro" pode expressar uma situação ideal que deveria acontecer ou a qual desejam chegar, porém, acabam não se concretizando em função de não estabelecerem relações consistentes e recíprocas.

\subsection{Visão da concorrência}

Sob a perspectiva de competição as empresas vêem os demais atores da dimensão horizontal como rivais e esta postura "consiste na busca por uma posição mais vantajosa sobre a concorrência" (MARCHI, 2006: 24). Na cooperação como parceiros para troca de conhecimentos, criação de valor e benefícios mútuos. Na coopetição, os atores são vistos como coopetidores. Os entrevistados respondem, quanto à forma com que vêem os outros atores do setor de acomodação, que os vêem como parte do ambiente, considerando ou não a possibilidade de alcançar uma posição vantajosa sobre os demais.

Eu me considero assim, não exatamente um concorrente, [e sim] um participante. Por que eu reconheço que existem hotéis, esses 3 ou 4 hotéis principais da nossa cidade, que eu não poderia, concientemente, não poderia concorrer, mas simplesmente me comunico, participo com eles e sou muito bem aceito. (ENTREVISTADO 4)

Em outras respostas percebe-se que há concorrência mas a possibilidade de estabelecer parcerias que produzam benefícios para ambas as partes não é descartada. Esta situação pode ser relacionada à dinâmica de coopetição, uma vez que podem ser estabelidas parcerias com outros atores e, ao mesmo tempo, competir.

Vemos como parte do negócio, quando possível formamos alguma parceria que traga benefício para nós, para eles e principalmente para os clientes. (ENTREVISTADO 5)

Há também a visão de que, mesmo estando inseridos em um ambiente de competição, não são diretamente concorrentes, uma vez que atendem públicos distintos. 
A nossa empresa aqui é uma empresa muito antiga. É um ambiente familiar. $\mathrm{O}$ ambiente de concorrência, é diferente, eu não vejo como concorrência. É outro público. Eu não vejo como rivais. (ENTREVISTADO 7)

Da mesma forma, outro respondente declara ver as empresas como complementares, porém, percebe-se, em sua resposta que há um comportamento de desconfiança frente aos demais atores.

\begin{abstract}
$\mathrm{Na}$ verdade não existe concorrência e sim complementariedade de atividades afins. Devido a desarticulação do setor, principalmente pela ausência de lideranças (públicas/privadas) existe uma certa competição (ignorância) por parte da hotelaria ao não fornecerem informações sobre as outras alternativas disponíveis na fronteira (pousadas /fazendas/ vinícolas/ CTGs/ sítios/ Haras/ etc.). Existem espaços para todos, desde que exista qualidade nos serviços e treinamentos sobre a correta divulgação, aí todos ganham. (ENTREVISTADO 9)
\end{abstract}

Isoladamente, obteve-se uma resposta que considera os concorrentes como parceiros. Porém, esta declaração pode ser insustentável por não ser verificada na prática.

Vejo como parceiros (ENTREVISTADO 2)

De modo geral, percebe-se, entre os entrevistados, que estes possuem uma visão de competição com as outras empresas e que em poucas situações aconteceriam parcerias que melhorassem sua competitividade frente aos outros concorrentes, uma vez que suas atitudes limitam-se à criação de valor individual (interna) e não nos processos comuns com outras empresas.

\title{
4.10 Relação entre empresas
}

Nas relações entre as empresas, sob a dinâmica da competição, "o sucesso competitivo e a apropriação de valor entre as empresas, ou a derrota e a perda de valor de outras, são baseados em um jogo de soma-zero" (MARCHI, 2006:27). Na dinâmica da cooperação "a origem da competitividade das empresas está localizada dentro das estruturas de interdependência" (MARCHI, 2006:29) que é baseada em um jogo de soma-positiva. Na coopetição " $a$ interdependência das empresas está baseada em um jogo de soma-positiva-variável, que pode trazer benefícios mútuos, mas não benefícios necessariamente justos para os sócios por causa 
das várias pressões competitivas, que podem extinguir a estrutura cooperativa das empresas”. (MARCHI, 2006:31) Não observou-se, com base nas respostas dos entrevistados, uma relação de soma-zero, onde, necessariamente, um tem que perder para o outro ganhar. Da mesma forma, mas considerando outras respostas como as obtidas na variável "fonte de valor", não podemos considerar a existência de um jogo de soma-positiva pois não há uma relação de cooperação formal, como mostra um dos entrevistados.

Em livramento tá virando cada um por si, me dou bem com todas as empresas, me dou bem com todos os proprietários, mas nunca teve reuniões de hotelaria, então cada um deve fazer por si. Essa competição tem. (ENTREVISTADO 1)

Todavia, não pode-se dizer que há uma coopetição entre as empresas, visto que, no mesmo ambiente existem as pressões competitivas e, de uma forma muito sutíl, ações de cooperação ao indicarem outros hotéis, mas isto só ocorre quando operam com toda a sua capacidade. Mas declaram ter um bom relacionamento com os demais atores da conurbação, como mostram algumas das respostas.

[...] são colegas, acima de tudo são colegas, não se enfoca como rivais, se enfoca como outro válvula de escape que também gira no mesmo ramo que nós. Mas acredito que nenhuma cidade vai pra frente se não se trabalhar em equipe hoje. Não temos como trabalhar de forma isolada. (ENTREVISTADO 3)

\subsection{Intensidade das relações}

A intensidade das relações, segundo Marchi (2006) pode ser curta quando as empresas atuam sob uma dinâmica de competição; duradouras quando sob uma dinâmica de cooperação; e flexível quando sob uma dinâmica de coopetição.De modo geral, sobre a intensidade das relações, as respostas foram bastante diversificadas, sendo que, dentre as nove empresas, duas mantém relações mais curtas, três relações mais flexíveis e quatro relações mais duradouras. Relações mais curtas podem ser observadas nas afirmações seguintes.

Sempre pesquiso preços, se se adequar preço, bárbaro. Sempre vou procurar preço. (ENTREVISTADO 6) 
Foi percebido maior flexibilidade na intensidade das relações nestas respostas:

\begin{abstract}
Variam na sua intensidade de acordo com o grau de abertura e afinidade entre as empresas, uma vez que não existem aproximações induzidas pelas entidades de classes e poder público (Prefeitura). (ENTREVISTADO 9)
\end{abstract}

E, por fim, relações mais duradouras em outras afirmações.

Geralmente é duradoura, a gente procura sempre perpetuar, cada vez mais, os fornecedores. É muito difícil a gente fazer alguma troca em pouco período de tempo. A gente antes de trocar faz uma consulta, conversa e vê se tem conta para negociar para que fique uma parceria boa. (ENTREVISTADO 8)

Levando em consideração os conceitos de Marchi (2006), em uma dinâmica de cooperação prevalecem entre os atores relações mais duradouras. Porém, não pode-se dizer que as empresas cooperam com os demais atores do setor de acomodação, uma vez que estas relações duradouras limitam-se basicamente às relações com fornecedores.

\title{
4.12 Comportamento das empresas
}

Dagnino \& Padula (2002) afirmam que oportunismo e confiança são variáveis comportamentais, geralmente coexistindo no mesmo contexto em diversos graus, que vão desde um nível de desconfiança até uma forte confiança, influenciadas pelo tempo e intensidade das relações. Marchi (2006) considera que o comportamento das empresas é de oportunismo e desconfiança na dinâmica da competição, de ajuda mútua e compromissos na cooperação e na coopetição suas ações são de reciprocidade podendo ou não alcançar confiança.

Seguindo as características de cada dinâmica quanto ao comportamento das empresas, observa-se inicialmente um grau de desconfiança entre os atores, não só do setor de acomodação, como também do setor de atrações (como podem ser considerados os free shops), ao mesmo tempo que afirmam ser importante colaborar com os mesmos.

A gente é plenamente independente, a gente não tem ajuda de ninguém. Só nós. [Estamos] abertos plenamente para negócios. (ENTREVISTADO 6) 
No mesmo sentido, o entrevistado 2 reafirma a importância de colaboração, mas não deixa de declarar que esta relação ocorre quando está com sua capacidade de acomodação plena. Outro ponto relevante a ser comentado é que surge uma preocupação com a imagem do destino como um todo.

Pra mim é ajuda mútua, sei que às vezes nem todo mundo corresponde a isso. Mas eu faço parte deste ponto de vista, de ajuda mutua, já tenho tido exemplos positivos, continuo a acreditar. Parceira com os próprios colegas, [...] muitas vezes no nosso ramo de hospedagem, conforme a procura, às vezes nós já estamos lotados, ligamos pro outro colega oferecendo, porque nós temos que procurar receber bem o nosso hóspede, o nosso turista, o que vem em trânsito, e não dificultar. Se eu não tenho lugar no meu hotel hoje, [...] eu procuro acomodar em outro hotel para que ele tenha uma boa imagem da nossa cidade como um todo. (ENTREVISTADO 2)

Surge novamente a influência de normas e valores e sentimento comunitário no comportamentos das empresas. Como pode-se notar, há uma pré-disposição para colaborar com causas sociais.

Existe a relação comercial sem deixar o lado humano. Sempre que preciso a empresa está aberta para ajudar a comunidade. É uma relação para o lado comercial sempre que o outro lado não me diz que a empresa se ponha a disposição para colaborar com a sociedade propriamente dita. (ENTREVISTADO 3)

Como característica da coopetição, a reciprocidade pode ser observada, porém, ocorre na relação com fornecedores e não com empresas concorrentes.

Temos com alguns fornecedores uma relação de muitos anos. (ENTREVISTADO 5)

Em suas respostas, dois entrevistados estendem seus comportamentos de desconfiança para além do ambiente de concorrência e abrangem outros setores da indústria do turismo, como os órgão municipais, estaduais e federais, bem como outras organizações presentes no ambiente.

O que mais poderia evoluir é o lado de investimentos [advindos de órgãos públicos] do lado de Santana do Livramento quanto ao turismo, porque tu vai para o lado de Rivera e eles são muito mais evoluídos do que a gente, 
aqui. Em qualquer mobilização voltada ao turismo, eles te abrem as portas de qualquer maneira, são muito avançados. E aqui do lado de Santana do Livramento falta muito ainda [...] (ENTREVISTADO 8)

Percebe-se que os entrevistados demonstram graus significativos de confiança dentro do setor estudado, resultando em relações curtas e esporádicas, impulsionadas em parte por vínculos de amizade, e que só ocorrem quando não é mais possível obter vantagens, em função da disponibilidade de recursos ser limitada, como ocorre quando não há mais capacidade de acomodação.

\section{Conclusão}

Com a análise das variáveis abordadas pôde-se investigar comportamento estratégico das organizações do setor de acomodação na indústria do turismo, da conurbação Fronteira da Paz. Inicialmente, as normas e valores dos empresários influenciam no relacionamento entre os hotéis, e, percebeu-se que são preservados valores como amizade, mas não chegam a formar parcerias em função de não atingir níveis de confiança e reciprocidade com os outros atores. já com os fornecedores aparecem mais relações de comprometimento, ainda assim, baixos níveis de confiança. Os níveis de desconfiança com os empresários que possuem atividades iguais é considerado alto, tanto que não foram estabelecidas parcerias que poderiam ser consideradas proveitosas, visto que as relações comerciais podem garantir o desenvolvimento dos negócios e as emocionais a preservação de normas e valores. Nota-se que o sentimento de envolvimento com a comunidade/destino é importante para a preservação destes valores comuns da comunidade, porém é importante ter, simultaneamente à este envolvimento, atitudes racionais, comerciais, para garantir novos investimentos.

Pode-se notar, também, que as normas e valores são levados em consideração no funcionamento do negócio, refletindo um comprometimento das empresas com atendimento ao cliente, qualidade de produtos e serviços à eles ofertados e investimento em melhorias para o negócio, entendido como "fim em si mesmo" mas sem deixar de visar o lucro.

Quanto às redes de relacionamento que as empresas estão inseridas, tanto com os outros atores como com os clientes, apesar de mencionarem predominar uma rede de negócios, constatou-se que as empresas, em sua maioria, se relacionam informalmente, caracterizando uma rede social. A estrutura da rede de clientes e as atividades de marketing são externas, 
visto que são empresas do setor de acomodação e seus clientes são de fora da comunidade. Quanto às compras, pode-se notar a preocupação em desenvolver o comércio e a mão-de-obra local. A estrutura de rede com fornecedores externos foi detectada nas empresas que atuam em outros segmentos simultaneamente.

Percebeu-se a coexistência dos diferentes modelos de negócio no mesmo ambiente, com predominância do modelo de competição. Porém, não ocorre em sua forma pura, uma vez que podem ser observadas, em algumas situações, atitudes de relacionamento informais interfirmas.

Já no pensamento estratégico, com a análise isolada respostas, os entrevistados afirmam pensar estratégia sob a perspectiva "macro". Porém, percebeu-se que suas atitudes são contrárias às suas afirmações, uma vez que as relações com os demais atores não atingem níveis consideráveis de comprometimento e confiança, não trabalhando uns com os outros em benefício do destino. Ao relacionarmos a variável "pensamento estratégico" com a "fonte de valor", confirma-se, entre os entrevistados, esta contradição no seu comportamento, visto que afirmaram que a fonte de valor é interna.

A visão da concorrência que possuem é de competição com as outras empresas, e em poucas situações aconteceriam parcerias que melhorassem sua competitividade frente aos outros concorrentes, uma vez que suas atitudes limitam-se à criação de valor individual (interna) e não nos processos comuns com outras empresas. Apesar da visão ser de competição ocorrem, de uma forma muito sutíl, ações de cooperação como quando indicam aos turistas outros hotéis, mas isto só ocorre quando operam com toda a sua capacidade. Não pode-se dizer que há uma coopetição entre as empresas, visto que, as relações de cooperação nao são formais.

Quanto à intensidade das relações, observou-se os três intensidades: curtas, flexíveis e duradouras. Redominaram as respostas em que os entrevistados responderam ter relações mais duradoura, porém não caracteriza-se como cooperação, visto que estas relações limitamse aos fornecedores, e não às relações com os atores com atividades semelhantes.

Por fim, quanto ao comportamento das empresas com percebe-se, entre os entrevistados, que as empresas não atingem graus significativos de confiança dentro do mesmo setor (acomodação), resultando em relações curtas e esporádicas, impulsionadas em partes por vínculos de amizade, e que só ocorrem quando não é mais possível obter vantagens, em 
função da disponibilidade de recursos ser limitada, como ocorre quando não há mais capacidade de acomodação nos seus hotéis.

\section{Referências}

AGOSTINHO, M. (2003) Administração complexa: revendo as bases científicas da administração. RAE-eletrônica, Vol. 2, N. 1, jan-jun.

ANSOFF, H. I. (1983) Administração Estratégica. São Paulo: Atlas,

BARQUERO, A. V., (2001) Desenvolvimento endógeno em tempos de Globalização. Porto Alegre: Fundação de Economia e Estatística,.

DAGNINO,G. B., PADULA, G. (2002) Coopetition strategic: towards a new kind of interfirm dynamics. In: The European Academy of Management. Stockholm: Second annualconference innovative research in management, May.,

DAS, T. K., \& TENG, B. S. (2001). Trust, control and risk in strategic alliances: an integrated framework, Organization Studies, 22(2), 251-283.

DYER, J.H.; SINGH, H. (1998) The relational view: cooperative strategy and sources of interorganizational competitive advantage. Academy of Management Review. New York, USA oct.

GONZÁLEZ, L. (2003) Cooperación y empresas: retos, presente y futuro. España: Thonson, 2003.

GRÄNGSJÖ, Y. von Friedrichs (2003), "Destination networking: co-opetition in peripheral surroundings", International Journal of Physical Distribution \& Logistics Management, Vol. 33 No.5, pp.427-48.

GULATI; R., NOHRIA; N., ZAHEER. (2000) Strategic Management Journal, Vol. 21, No. 3, Special Issue: Strategic Networks. Mar. pp. 203-215

HAIR Jr., J. et al.(2005) Fundamentos de métodos de pesquisa em administração. Porto Alegre: Bookman,.

HITT, M. A.; IRELAND R. D.; HOSKISSON, R. E. (2002) Administraçao Estratégica: competitividade e globalização. São Paulo: Pioneira Thomson Learning.

HOFFMAN, N. P. (2000) An examination of the "sustainable competitive advantage" concept: past, present, and future. Academy of Marketing Science Review. Alabama: University of Alabama.

LADO, A. A.; BOYD, N.G.; HANLON, S. C. (1997) Competition, Cooperarion and the Search for Economic Rents: a syncretic model. Academy of Management Review, n.1, p.110-141,

LEÃO, D. A. (2004) Relevância da Teoria da Coopetição para a Compreensão da Dinâmica dos Relacionamentos entre Empresas Concorrentes. (Mestrado em Administraçao) - Centro de Ciencias Sociais Aplicadas, Departamento de Ciencias Administrativas, Universidade Federal de Pernambuco. UFP, Recife

LEITE, A. L. M; TUROLLA, F. A. (2006) A força do turismo. GV Executivo, São Paulo, v. 6, n. 4, p.16-22, jul./ago.

MARCHI, J. J. (2006) Redes empresariais: um estudo comparativo dos fatores sócio-comportamentais e desempenho competitivo em duas redes de empresas do varejo alimentício. Mestrado em Administração - Universidade Federal de Santa Maria.

MATTOS, J. F.; BELTRAND, M. V.; BERTÉ, R. S. (2002) Cooperar para Competir: o novo desafio da competitividade. MBC/Sebrae. Porto Alegre, 
MIDDLETON, V. T. C. \& CLARKE, J. (2002) Marketing de Turismo: teoria e prática. Rio de Janeiro: Elsevier.

MINTZBERG, H. (2003) Criando organizações eficazes. São Paulo: Atlas.

NALEBUFF, B.; BRANDENBURG, A. (1996) Coopetição. Um conceito revolucionário que combina competição e cooperação. Rio de Janeiro: Rocco.

PORTER, M. (1979) How competitive forces shape strategy. Harvard business Review, march april, 1979.

PORTER, M. E. (1980) Competitive strategy: techniques for analyzing industries and competitors. New York: Free Press.

PORTER, M. (1989) Vantagem Competitiva: criando e sustentando um desempenho superior. 17 ed. Rio de Janeiro: Campus.

POWELL, W.W.; KOPUT, K.W.; SMITH-DOERR, L. (1996) Interorganizational collaboration and the locus of innovation: networks of learning in biotechnology, Administrative Science Quarterly, New York, USA, v. 41, n. 1, p.116-145, mar.

SAUAIA, A. C. A; KALLÁS, D. (2007) O Dilema Cooperaçăo-Competiçăo em Mercados Concorrenciais: o Conflito do Oligopólio Tratado em um Jogo de Empresas. RAC - Revista de Administração Contemporânea, São Paulo, v. 11, 1ª Edição Especial, p.77-101.

SILVEIRA, M. A. T. (2002) Turismo, Políticas de Ordenamento Territorial e Desenvolvimento. Um foco no Estado do Paraná no Contexto Regional. Tese (Doutorado em Geografia) - Faculdade de Filosofia, Letras e Ciências Humanas da Universidade de São Paulo. USP, São Paulo.

TEIXEIRA; C. H; (2007) Identificação de Competências Organizacionais Brasileiras no Processo de Internacionalização e Inserção Competitiva no Mercado Global. 170 f. Dissertação de Mestrado (Mestrado em Administração de Empresas) Faculdade de Economia e Administração da Universidade de São Paulo. USP, São Paulo.

VENTURA, M. M. (2007) O Estudo de Caso como Modalidade de Pesquisa. Rev SOCERJ. 20(5):383-386.

WANG, Y.; KRAKOVER, S. (2007) Destination marketing: competition, cooperation or coopetition?. International Journal of Contemporary Hospitality Management, v. 20, n. 2, p. 126-141.

POWELL, W. W. Neither market nor hierarchy: network forms of organization. Research in Organization Behavior. v. 12, p. 295-336, 1990.

\section{Recebido em: 17/02/2012 (1 ${ }^{\mathrm{a}}$ versão) $22 / 03 / 2013$ ( $2^{\mathrm{a}}$ versão) Aprovado em: 09/08/2013}

